\title{
Professional formation of the teachers under the conditions of digital transformation of higher education
}

\author{
Svetlana Belovitskaya ${ }^{1 *}$, Tatyana Guseva ${ }^{2}$, Irina Shatokhina ${ }^{2}$, Elena Shcherbina $^{2}$ and \\ Mohammed Kadom Mahdi Al Hussini ${ }^{3}$ \\ ${ }^{1}$ Don State Technical University, 344003, Rostov-on-Don, Russia \\ ${ }^{2}$ Southern Federal University, 344006, Rostov-on-Don, Russia \\ ${ }^{3}$ Baghdad University, College of Physical education, Baghdad, Iraq
}

\begin{abstract}
The article is devoted to the problem of using digital technologies for the professional formation of future primary school teachers. The authors note the relevance of this problem in connection with the digital transformation of higher education. It is emphasized that both Russian and foreign researchers define professional competence as the leading feature of professional development in the conditions of digitalization of education, reflecting all aspects of the professional activity of a teacher. In the article, the authors describe an effective way of using digital technologies for the professional formation of primary school teachers. Based on the content analysis of the regulatory database and scientific researches, it is noted that the study of this problem in the system of Russian higher pedagogical education is a separate direction under study linked both with the prospective development of education as a whole and risk factors. The article substantiates the need for professional formation of the future primary school teachers under the conditions of digitalization of the educational process and traditional forms of education. The authors have developed a model of professional formation of future primary school teachers under the conditions of digitalization of higher pedagogical education, and presented the components of digitalization of higher pedagogical education. This research is addressed to the teaching staff of higher educational institutions, and to future teachers.
\end{abstract}

\section{Introduction}

The intensive digitalization as a component of the socio-economic development of many countries causes qualitative changes in the field of production in the world market. These changes have created challenges to modern education. The digital transformation of higher pedagogical education today is considered as an inevitable factor of changing the educational content, pedagogical principles, methodological approaches and forms of professional formation of future teachers, in particular primary school teachers.

\footnotetext{
* Corresponding author: belovickaja-svetlana@rambler.ru
} 
The process of global digitalization makes high demands on the educators. For example, a primary school teacher is considered to be a specialist who, on the one hand, is able to provide a high quality of education for primary school students, while maintaining the fundamental character of Russian education and its relevance to the current needs of society. On the other hand, the primary school teacher should identify the personal characteristics of students and organize the educational process making them interested in acquiring knowledge.

In her research, K. M. Chugaeva examines the theoretical aspects and prospects for the development of the higher vocational education through the implementation of digital technologies and platforms in the learning process, aiming the formation of professional competencies of future specialists at the request of Russian and international companies [1]. It should be noted that this approach to higher pedagogical education makes it possible to form such professional competencies of a future primary school teacher as: psychological and pedagogical, subject-oriented, methodological and communicative ones.

Digitalization provides the students of higher education institutions with the opportunity to solve various types of educational tasks at different levels of individual abilities, which contributes to the effective professional formation of the future primary school teachers.

However, despite the benefits of digitalization of the higher professional education, the agents of the educational process may face some obstacles. In this regard, S. I. Belovitskaya, O. V. Granovskaya, and I. V. Shatokhina identify a number of difficulties connected with the use of blended learning technology "Flipped class" in the system of higher professional education:

- firstly, it is necessary to organize the workshop in such a way that it would contribute to the formation of students' universal learning actions which constitute their professional competence;

- secondly, when organizing the workshop online, it is necessary to create such learning situations that would provide productive learning activity of all students, taking into account their individual abilities and knowledge of the learning material;

- thirdly, the complex application of various teaching tools aimed at rational allocation of class time is inevitable, not only for studying new educational material, but also for mastering the ways of its application [2].

It is obvious, that in the modern world, obtaining professional education is associated with the use of certain digital educational technologies. The digital technologies can serve as a basis of creating an individual educational trajectory, which, on the one hand, meets the needs of professional formation of future primary school teachers, and on the other hand, becomes a driver of professional self-realization of students and teachers.

\section{The Concept and Methodology of the Study}

The study revealed the problem of the relationship between the professional formation of primary school teachers and the operational tasks of digital transformation of the higher vocational education in the Russian Federation.

Based on this, we can assume that the digitalization of higher pedagogical education contributes to the professional formation of future primary school teachers.

The purpose of the article is to determine the effectiveness of the use of digital technologies in the system of higher vocational education for the professional formation of future primary school teachers

The empirical sample includes legal educational documents, presented in the reference legal system Consultant Plus, the Internet version of the Garant system, as well as scientific works in the field of higher vocational education and its digital transformation. 
Research methods: cluster analysis, content analysis, generalization, comparative analysis, interpretation.

\section{Results and Discussion}

At the first stage of the study, we try to determine the information resource that ensures the digitalization of higher vocational education in the Russian Federation. The Decree of the Government of the Russian Federation No. 1836 on November 16, 2020 "On the state information system "Modern Digital Educational Environment" speaks of the importance of creating the state information system. This system is considered as a single information portal that should provide access to various educational platforms, where young professionals and future specialists will have the opportunity to study different online educational courses.

Considering the digital transformation of higher pedagogical education, it is necessary to identify significant changes in professional pedagogical activity. Digitalization of education significantly changes the sphere of knowledge, information perception and educational activity of students. At the same time, the digital transformation of the higher professional education system, being one of the tools of the educational process, is a kind of new educational environment that includes innovative and traditional learning requirements.

The methodological recommendations on ensuring the minimum level of digital readiness of educational institutions of higher education (EIHE), approved by the Ministry of Science and Higher Education of the Russian Federation on November 18, 2020 state that the digital readiness of EIHE means the availability of functioning hardware infrastructure, systemic and applied software, as well as compliance with information security requirements that provide conditions for the implementation of educational programs of higher education, basic vocational training programs, continuing education programs with the use of e-learning and distance learning technology.

Based on the above, we have developed a model of professional formation of future primary school teachers under the conditions of digitalization of higher pedagogical education (see Fig. 1).

According to Meskhi B., Fedotova O., Platonova E., Belovitskaya S., B. Cornu, E. Yu. Levina, Ogaylo Kuzu, D. Evalt, the intensive development of information and digital technologies causes a huge need for their application, including in the field of education [3, $4,5,6,7]$. The present-day system of higher pedagogical education implies scientific and applied trends connected with the use of digital technologies in the vocational training. This contributes to such conditions, as:

- the teaching staff develops scientific and methodological tools for the support of the professional development of future primary school teachers;

- students get the opportunity to reveal their own cognitive potential with the help of modeling their educational trajectory.

Presented in Figure 2 components of the digitalization of higher pedagogical education are considered to be an educational environment that serves as a condition for qualitative changes in the professional competencies of future primary school teachers (see Fig. 2).

In our opinion, a higher education institution is the basis for high-quality digitalization of the educational environment, since it is in the university that two potential clusters are combined: educational and scientific. 


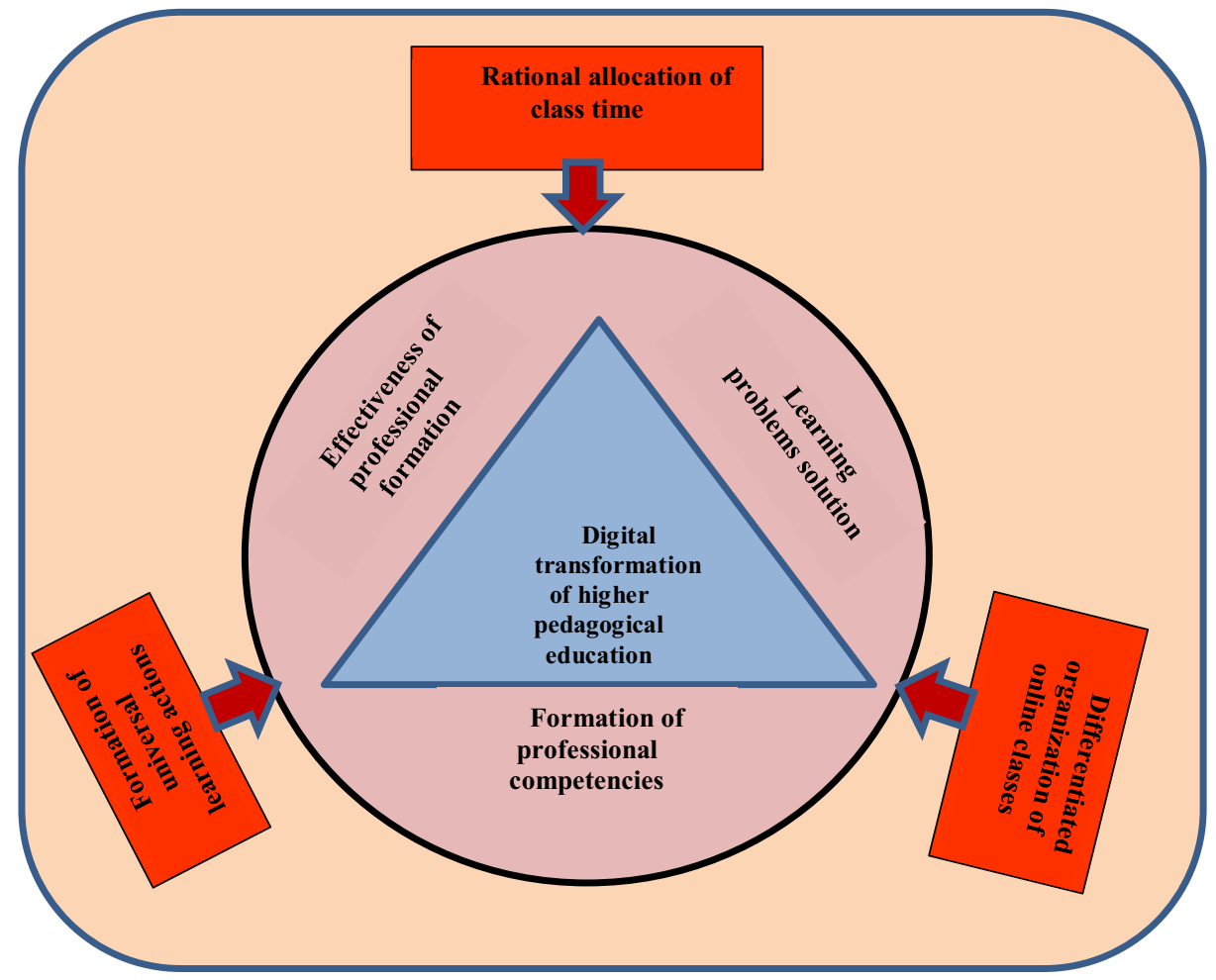

Fig. 1. The model of professional formation of future primary school teachers under the conditions of digitalization of higher pedagogical education.

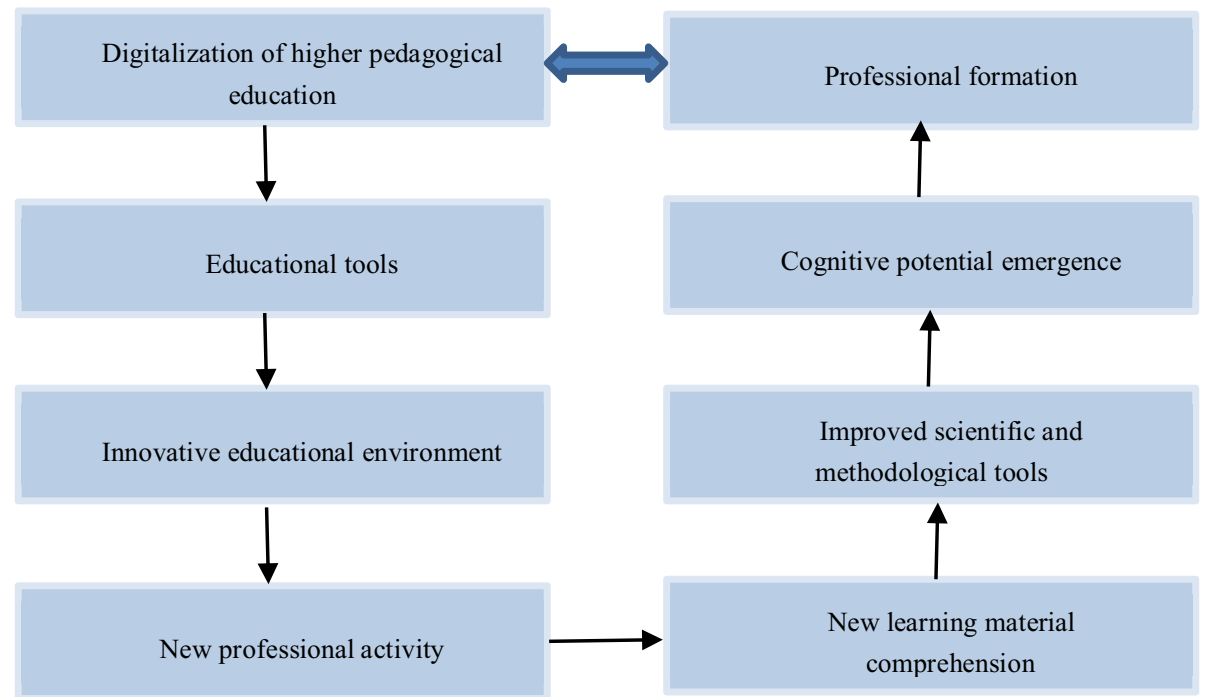

Fig. 2. Components of the digitalization of higher pedagogical education.

The analysis of the Order of the Ministry of Science and Higher Education of the Russian Federation on December 25, $2020 \mathrm{~N} 1580$ "On Approval of the List of organizations Classified as Federal Innovative Platforms that make up the innovative infrastructure in the field of higher education and the corresponding additional professional education", revealed 
that a number of higher educational institutions of the Russian Federation belong to federal innovative platforms where new educational infrastructure is being organized. For example, the Ufa State Petroleum Technical University has developed an integrative model of engineering education in order to form a system of professional competencies of the teachers of Science. The list of organizations classified as federal innovative platforms, according to this Order, is 127 higher educational institutions, of which 10 organizations are higher educational institutions. The result of the analysis is shown in Figure 3.

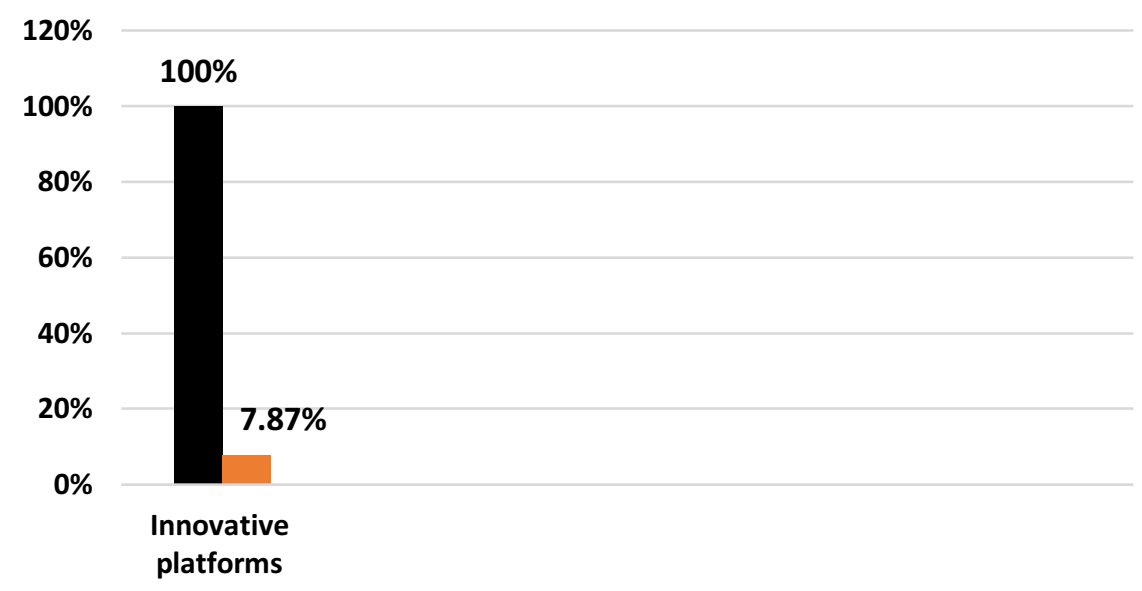

- Organizations classified as federal innovative platforms (127 istitutions)

\section{Higher educational organizations classified as federal innovative platforms (10 istitutions)}

Fig. 3. The percentage of higher educational institutions classified as federal innovative platforms.

The histogram shows that among 127 institutions of higher professional education classified as federal innovative platforms from years 2021 to 2023-25, the percentage of higher pedagogical institutions is $7.87 \%$.

The second stage of the analytical study connected with the definition of goals and a system of pedagogical measures contributing the professional formation of future primary school teachers under the conditions of the digital transformation of vocational educational. We considered the sufficiency of the use of digital technologies for the formation of professional skills of primary school teachers.

Digitalization of the system of higher pedagogical education requires the solution of the following pedagogical tasks:

- creating new educational conditions for the professional formation of primary school teachers by using the potential of digital technologies;

- development of students' cognitive potential, namely their logical and algorithmic thinking, by means of the digitalization of the educational process;

- improving the university teachers' professional competence in the organization of digital education of students.

It is important to note that during the digital transformation of the system of higher pedagogical education, the development of internal motivation of the future specialists to use digital technologies both for professional development and personal growth is fundamental. The knowledge-centered paradigm of teacher training is shifting to a constructive search of knowledge due to digitalization. However, it is necessary to conclude that the readiness and ability of future primary school teachers to professional activity are formed on the basis of 
both obtaining certain knowledge while learning communication with the lecturer and groupmates, and constructive "building up" of this knowledge with the use of digital educational technologies.

Studying the problem of professional formation of primary school teachers, T. K. Guseva, N. K. Mayatskaya reveal the peculiar features and spiritual foundations of Russian teaching staff at the present stage [8]. According to them, it is urgent to develop the scientific and methodological support of both spiritual development of future primary school teachers and the formation of their skills of information retrieval by digital technologies. The solution to this problem connected with the use of various technologies of educational information conversion. This allows the future specialists to create their own concept of knowledge while studying a particular discipline, which, in its turn, contributes to the development of a professional worldview. According to G. V. Semenov, S. A. Timofeev, O. D. Fedotova, professional worldview considered as a practical task, which is the leading component of professional culture, reflecting all aspects of the activity of a specialist as a person and a professional and being the regulator of his activity and behavior [9, 10]. The professional formation of the future primary school teacher under the conditions of the digitalization of the educational process is a mental orientation of scientific and practical achievements, in which all the agents of the educational process participate. In this regard, it seems necessary to use digital technologies in the modern system of higher pedagogical education. We believe that the digital transformation of higher pedagogical education contributes to the improvement of the educational content, teaching and learning technologies and the effectiveness of the professional formation of future primary school teachers.

However, a number of scholars pay attention to the fact that along with the prospects for digitalization of higher pedagogical education, there are also risk factors for the formation of students' innovative thinking [11-17].

In her research, N. B. Strekalova confirms the need to form students' digital competencies, make changes in the content of professional training, and equip university teachers with appropriate knowledge, skills, and competencies. At the same time, the scientist speaks about possible negative changes in this area (loss of basic cognitive competencies, reduction of the general level of vocational training, reduction of the need for an "intellectual" specialist, loss of the fundamental nature of university education, redistribution of functions of university administrators and teachers, high requirements for the personality properties of lecturers, reduction of personal contacts, conflicts escalation, international brain drain, loss of the higher education status, reduction of the number of university students) [11].

Taking into account the studied prospects and risk factors for the digitalization of higher pedagogical education, we can conclude that the professional formation of future primary school teachers is provided with the involvement of both the teachers and the students into the theoretical and practical aspects of the discipline being studied.

\section{Conclusion}

Based on the above and the analysis of scientific research conducted by I. V. Andronova, N. V. Lapteva, O. P. Osipova, A. B. Baymakhanova, D. S. Dmitriev, we can conclude that we have considered only a part of the issues related to the digital transformation of higher pedagogical education. It is obvious, that the professional formation of the future primary school teachers under the influence of digitalization of the educational process is at the stage of development. Digitalization encourages the higher education system to use information technologies, and, in the current situation of world restrictions, solves a number of organizational problems. However, the only use of digital technologies in the system of higher pedagogical education can not solve global problems of vocational training. They will also have to be solved with the help of Offline training. 
In the study, we have revealed the problem of the professional formation of future primary school teachers with the use of digital technologies in the system of higher pedagogical education, and also determined that the effectiveness of professional training depends on the combining traditional and innovative approaches to education.

\section{References}

1. K.M. Chugaeva, Prospects of digitalization of higher professional education in the Russian Federation, In: Chugaeva K. M. (eds.) Actual problems and prospects of development of radio engineering and infocommunication systems "Radioinfokom2019". Vth International scientific and practical conference 2019, Mirea, Russian technological university Moscow, 518-521 (2019)

2. S.I. Belovitskaya, O.V. Granovskaya, I.V. Shatokhina, TDSE 66(4), 16-20 (2020)

3. B. Meskhi, O. Fedotova, E. Platonova, S. Belovitskaya, Overcoming barriers to teaching Russian as a non-native language among younger students in certain regions of the North Caucasus, In: INTED2019 13th International Technology, Education and Development Conference. Conference proceedings. 4752-4756 (2019)

4. B. Cornu, Digital natives: how do they learn? How to teach them? Policy brief UNESCO Institute for Information Technologies in Education. (2011) https://unesdoc.unesco.org/ark:/48223/pf0000216681 (last accessed 2021 /21/03).

5. E.Yu. Levina, Kazan Pedagogical Journal 5(136), 8-14 (2019)

6. O. Kuzu, Higher education in Russia 3, 9-23 (2020)

7. D. Edalt, The most innovative universities in Europe-2017. http://www.reuters.com/article/us-reutersrankings-europeanuniversities / Europesmost-Innovative-University-2017-idUSKBN17Z09T, last accessed 2021/21/03.

8. T.K. Guseva, N.K. Mayatskaya, PSFU (PS) 8, 32-38 (2012)

9. G.V. Semenov, S.A. Timofeev, O.D. Fedotova, The world of science. Pedagogy and psychology. https://mir-nauki.com/PDF/62PDMN120.pdf, last accessed.

10. O. Fedotova, O. Chigisheva, International Perspectives on Education and Society 26, 57 $82(2015)$

11. N.B. Strekalova, Bulletin of the Samara University. History, pedagogy, philology. 2, 84 88 (2019) doi.org/10.18287/2542-0445-2019-25-2-84-88.

12. I.V. Andronova, N.V. Lapteva, Saratov university proceedings. New part. Sociology part. Political science 4(20), 464-469 (2020) doi.org /10.18500/1818-9601-2020-20-4464-469.

13. O.P. Osipova, O.A. Shklyarova, Teacher of the XXI century 2, 108-124 (2019)

14. A.B. Baimakhanov, E.A. Balabaeva, O.P. Osipova, E.V. Savenkova, Modern higher education: an innovative aspect 2(12), 78-90 (2020)

15. D.S. Dmitriev, Bulletin of the Samara State University 4(126), 192-196 (2015)

16. Alla Belousova, International journal of cognitive research in science engineering and education-IJCRSEE 8(SI), 29-36 doi.org/10.23947/2334-8496-2020-8-SI-29-36.

17. Biljana Novković Cvetković, Lazar Stošić, A. Belousova, Croatian Journal of Education 20(4), 1089-1114 (2018) doi.org/10.15516/cje.v20i4.3001. 